\title{
TOWARDS UNDERSTANDING LEARNING PATHWAYS: A TRANSDISCIPLINARY RESEARCH AND DEVELOPMENT APPROACH
}

\author{
T. Golja ${ }^{1}$, P. Barrett ${ }^{2}$ \\ ${ }^{1}$ University of Technology Sydney (AUSTRALIA) \\ ${ }^{2}$ Catholic Education, Diocese of Parramatta (AUSTRALIA)
}

\begin{abstract}
Research-practice partnerships in education are pioneering new ways in which researchers and teacher-practitioners work together on the basis of a mutually beneficial collaboration, a view of research as a core activity involving participants as co-researchers in their joint work, and where questions focus on practice for the betterment of learners. Transdisciplinary research and development extends such inquiry-driven, participatory approaches through integrating both non-academic participants (including industry, public and private sector partners, community members, policy makers, to name a few) and academic researchers from unrelated disciplines (including social sciences, natural sciences, arts, design and humanities, amongst others) to achieve a common goal - involving the creation of new knowledge, practices and theory - and transform insights into initiatives for the good of society. This paper arises from a university-school sector collaboration that set out to tackle the challenge of preparing young people cognitively and socially to choose the living of meaningful and productive lives, alongside the broader agendas of educating them to develop dynamic careers that can adapt to and create tomorrow's workforce and supporting their career-life aspirations. Growing out of previous collaborations and early conversations, this preliminary paper reports on a two-year project that we co-designed to implement novel transdisciplinary techniques and practices, test a proof of concept and discern its feasibility for career education, prototype and pilot initiatives centred on industry- and student-led challenge projects and co-designing virtual workspaces. These transdisciplinary developments would enable the university-school team to investigate questions such as how to grow and renew school-based capability for working with teachers, community, industry and families as they partner with students, working together for sound life choices, and to what extent such co-designed environments improve students' engagement with career pathways and development of future-oriented capabilities. As the project itself is dedicated to developing new valid, reliable and nuanced ways of measuring success in career advice provision, we lay out how participants might distil (research) quality and identify criteria that count toward developing a strong evidence base to inform practice and policy. We discuss the need for the next transdisciplinary phase of collective research and development if the project is to achieve its first milestone.
\end{abstract}

Keywords: Research-practice partnerships, learning pathways, transdisciplinary, boundary crossing, quality.

\section{INTRODUCTION}

Research-practice partnerships in education are pioneering new ways in which researchers and teacher-practitioners work together [1]. Such partnerships are built on the basis of a mutually beneficial collaboration, a view of research as a core activity involving participants as co-researchers in their joint work, and where questions focus on practice for the betterment of learners [1], [2], [3]. While challenging to bridge the different cultural worlds of researchers and practitioners who often have different priorities and agendas, these partnerships develop strategies for finding common ground and learning from one another [2]. That partnership activity, for example, can be viewed as a form of joint work requiring mutual engagement across multiple boundaries and developing an understanding of how differences are recognized and navigated [4]. Indeed, fostering such engagement amongst stakeholders with different perspectives represents a sea change in the way we think about research, practice, and the use of research to benefit children, youth, and families [5].

Transdisciplinary research and development extends such inquiry-driven, participatory approaches through integrating both non-academic participants (including industry, public and private sector partners, community members, policy makers, to name a few) and academic researchers from unrelated disciplines (including social sciences, natural sciences, arts, design and humanities, amongst others) to 
achieve a common goal - involving the creation of new knowledge, practices and theory - and transform insights into initiatives for the good of society. Though no two transdisciplinary research projects are alike, they fit within a broad framework that can be defined by six key parameters: the diversity of disciplines engaged, the depth of integration across disciplines, the degree of interaction with nonacademic stakeholders, the composition of non-academic stakeholders, the timing of participatory engagement, and the types of knowledge that are emphasised. The combination of these parameters is shaped by the problem to be addressed and may evolve over time [6]. In education settings, such transdisciplinary approaches can be viewed as a mechanism for innovation [7] underpinned by transdisciplinarity's basic principle of mutual learning (often described in terms of collaboration, collective learning, transformation, co-production, amongst others) [8].

This paper reports on a university-school sector collaboration - between the Faculty of Transdisciplinary Innovation (FTDi) at the University of Technology Sydney (UTS) and the Catholic Education, Diocese of Parramatta (CEDP) - to design a project that takes a transdisciplinary research and development approach in tackling the complex challenge of preparing young people cognitively and socially to choose the living of meaningful and productive lives, alongside the broader agendas of educating them to develop dynamic careers that can adapt to and create tomorrow's workforce and supporting their careerlife aspirations. We begin by briefly providing some background about this complex challenge, as situated in an Australian context.

\section{THE COMPLEX CHALLENGE}

In the 2019 National Career Education Strategy [9], three main groups - namely schools and systems, employers and community, parents and caregivers - were tasked with a shared responsibility for action in providing high quality career education. That action included building students' skills and capabilities, improving student engagement with work environments, supporting their transition to further education, training and work, and empowering them to make informed career decisions through their lives. At that time, CEDP was also undertaking a series of reviews [10], [11], [12] to firstly, explore current school practices locally and nationally, and secondly, to examine recent reports from OECD [13] and the Federal government [14] as well as academic publications [15]. They met with representatives from the newly formed National Skills Commission which had a brief to collect a range of data related to skills shortages in community and industry. And they scheduled focus groups with principals concerning challenges for curriculum engagement with students and families. Key findings from these CEDP reviews showed a need for curriculum designs and career advice structures that generally aligned with the framework of the National Career Education Strategy [9] and that supported students, families and industry to identify and select opportunities while at school which contribute to cognitive, personal and social development ready for post-school.

More broadly, various stakeholders have identified the challenge of preparing young people for work and life in this 21st century and taking shared responsibility. For example, the 2018 Australian Federal Government's Through Growth to Achievement report [16] set out recommendations upon which CEDP grounds its learning initiatives and development of learning pathways to enhance existing school and system activity. In particular, the recommendations included (1) laying the foundations for learning by engaging parents and caregivers as partners, and students as partners in their own learning; (2) equipping every student to grow and succeed in a changing world by acquiring general capabilities, strengthening community engaging and reviewing secondary schooling to equip students with skills for the future; (3) creating, supporting and valuing a profession of expert educators through high-quality professional learning; (4) empowering and supporting school leaders; and (5) raising and achieving aspirations through innovation and continuous improvement. Other recent reports and initiatives at Federal and State Government levels [17], [18], [19], [20] and from Industry [21], [22], [23], [24], [25], [26] identify challenges facing Australian education and addressing inequality, measuring capability and partnering for lifelong learning. For example, the 2017 Productivity Commission report Shifting the Dial [27] featured problems in ensuring the skill relevance of the existing workforce as more occupations are at risk of disruption, and when careers, employment and training opportunity information is fragmented. For CEDP schools, the findings and recommendations of these reports have informed and provoked a Learning Pathways approach, which has a vital role to play in transforming students with capabilities to continue learning over their lifetime.

Given these developments and priorities, it was most opportune when as part of the 2019-20 Federal Budget measure of "Delivering Skills for Today and Tomorrow", the National Careers Institute announced a Partnership Grants program specifically to address a seeming disconnect between the education and training sector and the needs of employers [28]. While the grant program was framed 
primarily in career-oriented terms, our underlying focus centers more on students gaining selfawareness to make their own best choices in life, which could include an existing career path or a wholly new path designed by the student over time. In this paper, we describe how as a university-school team we worked together to design a project grant proposal entitled Future Learning Pathways: Where to Now? that would address this complex challenge.

\section{A CONVERSATIONAL METHODOLOGY}

As a university-school collaboration, we adopted a conversational approach in designing the proposed project Future Learning Pathways: Where to Now? which aligned with the methodological principles developed by Cosgrove and Schaverien [29] and built on the recognition of its educational and educational research potential, summarized elsewhere [30] in the following terms:

- In educational settings, conversations with particular features (for example, where participants are agents, able to improvise and pursue their own questions in dynamic, emergent, free-flowing interactions [30], [31], [32], [33], [34], inquiring into their practice in professional communities [35], [36]) have been recognised as deeply powerful.

- Other studies [37] documented how conversations emerged and developed from individual perspectives and exploratory needs that occurred moment by moment as in natural conversation (see also [38]). Clark [33] described these characteristics similarly: "Conversation feels more like an exploratory, wandering walk around a mutually interesting place than a direct journey from one point to another. ... As a genre for learning and professional development, conversation groups have the wonderful quality of being controlled by the participants" (p. 181).

In our case, each participant could have an equal though different role in deliberately assisting the other "to pursue their own investigations, to help circumvent an obstacle to their thinking or to develop together a fruitful and related avenue of investigation or issue for discussion if ... [they] could see one, and with the benefit of ... [their] experience" (after [29], p. 108). Here, our work together extended such inquiry potential through integrating our different perspectives, knowledge, experiences and methods to yield a shared research and development agenda. Conversations were broadly framed by the grant guidelines and occurred primarily via telephone and email.

Taking this approach enacted the basic principle of transdisciplinarity, that is, mutual learning [39]. In effect, our university-school and research-practice partnership to frame this transdisciplinary research and development project proposal was a case in point of joint professional learning.

\section{FRAMING A COLLABORATIVE SCHOOL-UNIVERSITY PROJECT}

Educating Australians to develop dynamic careers that can adapt to and create tomorrow's workforce is a critical issue. Taking a transdisciplinary research and development approach, we framed our project Future Learning Pathways: Where to Now? to tackle that challenge and strengthen partnerships between industry, employers, schools and tertiary providers. Through implementing novel transdisciplinary techniques and practices, as a project we set out to (1) test a proof of concept, (2) discern its feasibility for career education, (3) prototype and pilot initiatives centred on industry- and student-led challenge projects and co-designing virtual workspaces, (4) generate a strong evidence base, and (5) propose a sustainable, systemic, future-oriented model for school renewal of career education and to inform government policy.

At a time when career pathways are becoming more complex and flexible, we intend to bring together diverse stakeholders - including young people/students, teachers, industry partners, public sector organizations, community members, Vocational Education and Training (VET) teachers, researchers, higher education professional staff, amongst others - to envisage and investigate how and why people might adapt to changing work and workplaces. We argue that these collaborative partnerships also provide a fertile basis for responding to emerging opportunities in creative, proactive ways that (1) create new jobs, (2) reframe work and life choices in a technological and rapidly changing world, (3) shape the future, and (4) produce regenerative societies and environments.

In short, squarely addressing the challenges faced in preparing tomorrow's workforce and supporting young people's career-life aspirations to make meaningful contributions, our proposed project uses a rigorous, creative transdisciplinary research and development approach for realizing cutting-edge initiatives. We turn now to describing some of the project's key activities and drivers to provoke the 
prototyping and piloting of this proof of concept for career education, which resulted from our initial conversations.

\subsection{What key activities emerged for this project?}

The first key activity centers on constituting a team of students, teachers, career advisors, community members, project-based Higher Degree Research students and researchers across three selected Catholic Education Diocese of Parramatta (CEDP) schools and building productive partnerships with industry, public sector organizations, local SME employers, the VET sector, UTS and other relevant stakeholders. Here, the UTS-CEDP project team uses a transdisciplinary approach in its consultation with industry-public organization sector-local SMEs-community partners and, with the school-based teams, co-designs complex challenge projects of high interest to a student cohort (e.g. a "passion" project) and of pressing need for industry or communities (e.g. an industry-led challenge), for example. They review existing best practice careers guidance and successful projects to distil key principles and practices for integration into this project or to use as a basis for leveraging new possibilities. Researchers refine transdisciplinary research designs and methodologies with stakeholders to ensure this project investigates questions of high interest to career education and career education research.

A second key activity focuses on prototyping and piloting of a series of experiential Challenge Projects, where school, industry-community, VET, university and other relevant stakeholders work together to explore viable learning pathways and generate productive headway on issues and problems of concern, curiosity and/or interest to them, and others. Here, researchers working alongside students, teachers and partners use creative methods and develop novel resources to support that mutual learning: including, for example, to understand and track the development and relevance of particular capabilities and create connections between school curriculum and real-life professional practice. From those collective experiential projects, stakeholders (students, industry-community partners and the project team) generate prototypes for (1) immersive online environments to connect their explorations with local and global agendas, and (2) industry-led workplace experiences. Further co-designed possibilities for consideration could emerge and generate new developments, resources and products.

A third key activity focuses on producing rich, agreed, case study accounts of the process of tackling complex challenges, successful mutual learning approaches, and generating and evaluating the range of prototypes, resources and products for career education. The sustained collaboration between diverse stakeholders - students, teachers, career advisors, industry partners, community members, VET teachers, researchers, amongst others - provide opportunities for eliciting insights into the project's research questions and inform the design of professional learning microcredentials and an open-access immersive environment to engage educators, career advisors and industry-community partners beyond this project and its three school sites. Analyzing the findings of these empirical studies also enable the project team to generate a model for school renewal of career education, which is sustainable, systemic and future-oriented.

The proposed project sets out clear synergies with current CEDP initiatives to engage young people in projects, opportunities and problems of high interest to them, as they work to respond to real challenges and make a difference in the world. Furthermore, given the innovative transdisciplinary educational programs and initiatives pioneered by the UTS: FTDi - and recognized by national industry and international education awards, amongst others - the project aims broaden the opportunity for schoolindustry-community-university research and development collaboration to tackle the complex challenge of career education in a rapidly changing world. In particular, to develop a contemporary understanding of learning pathways, the UTS-CEDP team seek to investigate questions such as: What are powerful and meaningful ways to work with school age students and their families in relation to career advice? How might we grow and renew school-based "career advisor" capacity and capability to work with teachers, community and families as they partner with students, working together for sound life choices? To what extent can co-designed virtual workspaces improve students' engagement with career pathways and their development of relevant capabilities? What counts as evidence? What might be the impacts and considerations of developing technologies (such as automation and artificial intelligence) on work and life (for example, [40], [41]) to the provision of career education programs? What insights into professional learning, research and the potential of new technologies (particularly, regarding scalability) can be gained from this project? 


\subsection{What drivers or principles formed to underpin the project?}

Initially, this project leverages off CEDP programs and approaches with proposed activities including designing and testing virtual workspaces (e.g. exploring virtual internships and work placement opportunities for students to gain a better understanding of professional workplaces, training and work requirements), growing capability at the site for career advice (e.g. co-designing professional learning opportunities and mutual learning with industry-community partners), developing parent engagement techniques (e.g. developing a careers information app for students and parents which aggregates publicly available information on demand about career path opportunities), tracking and reporting the progress of the Life Design model, for example, to note student learning pathway trajectories, and doing small-scale testing of career advice models (e.g. towards growing a sustainable, systemic, futureoriented model for school renewal of career education).

From the project team's view, how then might we address the demands of a rapidly shifting world of work and prepare for lifetime learning? As career pathways become more complex and flexible, we envisage and intend to investigate how and why people might adapt to changing work and workplaces, whilst also responding to emerging opportunities in creative, proactive ways that (1) create new jobs, (2) reframe work and life choices in a technological and rapidly changing world, (3) shape the future, and (4) produce regenerative societies and environments. To that end, our prototyping and piloting of a proof of concept for career education has at its core these starting drivers:

- As a transdisciplinary collaboration between school, industry and community and university, the project brings together diverse stakeholders including young people/students, teachers, industry partners, public sector organisations, community members, VET teachers, researchers, academic teachers, amongst others. As they work together to address a range of complex challenges - including career education - these stakeholders engage across disciplinary and professional practice to integrate different perspectives, methods, concepts, techniques, ideas and frameworks with the intention of generating new insights, opportunities, practices and initiatives.

- When confronted with uncertainty and rapid change, we recognize the value of instigating ways to think differently and imagine new possibilities, and in doing so, design transdisciplinary methodologies with stakeholders to reframe a complex challenge, see it anew, navigate that reconceived landscape and proactively design new pathways forward. Then, through prototyping and making those possibilities tangible, stakeholders work together in an immersive, experiential environment to trial and test a proof of concept through to realisation on a small scale. In the process, stakeholders refine their initiatives and make explicit how they distil quality over time.

- With its innovation-driven focus and using entrepreneurial approaches, this project explores and implements ways in which novel ideas can be realized to create value for individuals, communities, and society. That entrepreneurial thinking cycle shapes all aspects of this project, creating innovation ecosystems and seeding the next generation of entrepreneurial thinkers who can push beyond existing boundaries and limits.

- Coupled with its innovation focus, the project provokes all stakeholders to be inquiry-oriented to ask questions, identify opportunities, be curious, explore the unknown, experiment, learn from failures, take the power of learning into their own hands, become co-creators of new knowledge, and feel empowered to shape their own future. In that process, stakeholders explore the power of new ways of working with and thinking about learning, complexity, ecosystems, networks, and futuring.

- Through probing the nature and relevance of general capabilities in diverse, complex and dynamic situations, this project works to bridge school curriculum and real-life professional practice. Here, industry and community stakeholders come into the classroom to work with teachers and students on complex problems and opportunities, shaping how they collectively understand and track the learning of general capabilities such as critical and creative thinking, ethical understanding, complex problem solving and intercultural understanding in those real life situations. In the process, they explore future learning pathways and at the same time, begin to address, where to now?

Using the National Career Education Strategy (NCES) [9] as a guide, the UTS-CEDP project team is set to collaborate with school sites to contextually frame activities and implement the six NCES objectives, namely curriculum development and provision that (1) promotes transferable skill development, (2) meets the needs of all students, (3) establishes partnerships for learning, (4) engages 
community, (5) is informed and involved, and (6) has a strong evidence base. Furthermore, as part of that process, we intend to partner with the school system, employers/community and families to firstly, examine how the general capabilities developed at school might transfer, translate and/or transform into community and life settings and secondly, investigate how and why information from a strong evidence base might be integrated into school curriculum to meet the needs of all students.

\section{DISTILING QUALITY AND MEASURING PROJECT SUCCESS}

In the proposed UTS-CEDP project, we outlined a series of anticipated outcomes, coupled with considering ways in which we might gauge the quality of findings and measure its success.

\subsection{Anticipated outcomes}

A key project outcome is a sustainable, systemic, future-oriented model for school renewal of career education that advances the career development knowledge base - by using newly available technologies and those environments students, teachers, industry-community partners and researchers generate from them - to build subtly but powerfully different cultural forms for professional learning and career education. This model grows out of a series of prototyped and piloted initiatives bringing together industry, communities, schools, VET and universities in an immersive, experiential learning environment to tackle complex challenges together, and coupled with co-designing and realizing cutting-edge virtual workspaces and professional learning experiences. In those diverse settings, the skills and capabilities highly sought by employers and valued by communities are elicited to understand and track how futureoriented school curriculum bridges our society's prospective needs, priorities and opportunities. Furthermore, the project's transdisciplinary research and development approach constitutes a proof-ofconcept test in itself for career education, and a feasibility study for whether it can yield new insights into emerging careers and innovative ways of working. Such outcomes are of high value to educational institutions preparing young people for a lifetime of learning, as well as parents and caregivers, teachers and principals who support their aspirations.

A second outcome is a set of career education initiatives, together with the case study records of how they were generated, which also represent an advance of disciplinary knowledge in Education as they can be used as seeding resources for similar work within the CEDP system, and in other organizations, and as starting points and/or insights into sustainable career education and career education research generally. To that end, entrepreneurial and innovation ecosystem thinking shapes all aspects of this project to seed new ideas and push beyond existing boundaries and limits.

A third outcome incorporates new methodologies and technologies being developed whereby the project's design-based research approach itself constitutes a new methodology for career education as it introduces transdisciplinary approaches, methods and artefacts as research instruments and inquiry probes for both the project team and all participating stakeholders (including students, teachers, industry partners, community members, VET teachers, academics, researchers, amongst others). Conceivably, other already-developed career education environments and resources could be re-purposed for research and development in potentially fruitful ways. Such modularization is characteristic of technological contexts; and career education research and development approaches, like the present project with its co-design of virtual workspace environments and professional learning experiences, may well represent a significant methodological innovation, influencing the conceptual sophistication and flexibility of the educational research possible thus far. This approach is technological in its own right as well: here, these co-designed virtual workspace environments and professional learning experiences are mediating:

- Teachers' and career advisors' learning about industry and community skill needs and valued capabilities; student learning, development of those capabilities and aspirations, and; effective career advice support,

- Their learning about professional development and renewal, and

- All researchers' (students', teachers', industry partners', community members', and academics') learning about the project's agenda, methodology and resources, coupled with gaining insights into their shared research questions.

A fourth outcome involves technologies as professional learning environments including professional learning microcredentials and an open access short course that enable teachers to engage with the project's transdisciplinary approaches and generated educational resources - including its methods, 
techniques, frameworks, concepts and findings - and to further explore the implications for career education. A virtual workplace and/or virtual professional experiences as immersive environments for teachers' and career advisors' professional development may emerge as the scalability of the project products are explored.

\subsection{Gauging quality}

As the project team adopts transdisciplinary research methodologies and ethnographic social approaches, we intend to address how the quality of that qualitative research might be judged. There is no shortage of writings suggesting alternative ways of gauging quality and outlining strategies for ensuring trustworthiness of findings. For example, the success of qualitative research could be judged on criteria of

- Coherence, insight (or consensus) and instrumental utility [42].

- Its Illuminating effect ("its ability to reveal what had not been noticed"), its generativity ("its ability to promote new questions"), its incisiveness ("its ability to focus tightly on educationally salient issues and questions"), and its generalizability ("its relevance to phenomena outside of the research text") [43]

- Predictive accuracy, internal coherence, external consistency, unifying power, fertility and simplicity [44]

- Credibility, transferability, dependability, and confirmability [45]

- "... as giving us knowledge regarding human possibilities ... [and] what human beings might become in response to our research" (p. 262), thereby suggesting future-oriented interventionist value [46]

- Whether it could generate or develop theory, be empirically grounded and scientifically credible, produce findings that have utility in other settings and be internally reflexive [47]

All of these rubrics suggest plausible ways of gauging research quality in this project and generating a strong evidence base to inform policy.

\subsection{Measuring success}

Typical measurement strategies describe where we are now in relation to career advice provision and compare that to descriptions of the same at project end points. However, when the project itself is dedicated to developing new valid, reliable and nuanced ways of measuring skills and understandings of parents, students and employers, that approach is fraught. Our project's success therefore might conceivably be measured and described in different terms. For example, employers are able to articulate their own needs: not all employers have a future focus, and many are unable to see beyond replication of current business ideas to a different future that is beckoning (e.g. climate focused, green and environment friendly, locally producing on demand, reduced commuting). Parents gain understandings that the notion of work is changing with time, i.e. artificial intelligence, attitudes, communication technologies, discussions regarding a Universal Basic Income and its effect on all those factors (noting that the pandemic has hastened this thinking). Students have a voice and are heard in relation to a school education that values their interests and ideas and provides them time and meaningful recognition of what they can do, rather than what they cannot do. The CEDP has a clearer sense of staffing and resourcing schools to support the needs of students and families in relation to building capacity for making life choices. Of course, new ways of measuring student and teacher skills and capabilities that perhaps currently do not exist or are not recognized will also need to be addressed and could subsequently include a prototype system of micro-credentialling that is relevant to both students and employers, amongst others. Various strategies to take into account these success considerations are needed: in particular with relation to (1) working closely with teachers, students, community/employers and families to analyze current curriculum pedagogies and educational designs for relevance and the skills demands of employers, and (2) designing opportunities for internships and virtual professional workspaces, in consultation with industry and community stakeholders, that enables students to experience industry expectations for skill demand.

In all these ways, therefore, we seek to both distil research quality and improve the quality of career advice. 


\section{CONCLUSION}

In this paper we have given an overview of the transdisciplinary research and development approach taken to shape a school-university partnership's project and address a critical issue facing Australian society. In the next phase - A transdisciplinary proof of concept: Feasibility and generativity for career education - three CEDP schools are to be selected as project sites and a team of students, teachers, career advisors, community members and researchers constituted at each site with a network established across them. To meet the first milestone, one outcome to be achieved involves the design of a series of student-inspired and industry-led challenge projects. A second outcome includes the principles and practices distilled from a review of best practice careers guidance that provoked and shaped the co-designed projects, research designs and methodologies in preparation for subsequent implementation. A third outcome involves early case study records.

However, though this first milestone has been outlined and the principles underpinning the project's design and aspirations have been set to guide directions and pathways, when wider stakeholders and team members are brought into the conversations, other possibilities and agendas will emerge, shape developments and refine the research design and methodology. Through that transdisciplinary approach, this first phase of collective research and development involving diverse stakeholders seeks to generate a first test of the feasibility and generativity of a proof of concept for career education.

\section{REFERENCES}

[1] C. Coburn, and W. Penuel, "Research-practice partnerships in education: Outcomes, dynamics, and open questions," Educational Researcher, vol. 45, no. 1, pp. 48-54, 2016.

[2] C. Coburn, W. Penuel, and K. Geil, Research-practice partnerships: A strategy for leveraging research for educational improvement in school districts. New York, NY: William T. Grant Foundation, 2013

[3] W. Penuel, and H. Hill, "Building a knowledge base on research-practice partnerships: Introduction to the Special Topic collection," AERA Open, vol. 5, no. 4, pp. 1-5, 2019.

[4] W. Penuel, A. Allen, C. Coburn, and C. Farrell, "Conceptualizing research-practice partnerships as joint work at boundaries," Journal of Education for Students Placed at Risk (JESPAR), vol. 20, no. 1-2, pp. 182-197, 2015.

[5] V. Tseng, J. Easton, and L. Supplee, "Research-practice partnerships: Building two-way streets of engagement," Social Policy Report, vol. 30, no. 4, pp. 1-16, 2017.

[6] OECD, Addressing societal challenges using transdisciplinary research. OECD Science, Technology and Industry Policy Paper: OECD Publishing, June 2020. Retrieved from http://www.transdisciplinarity.ch/td-net/Aktuell/td-netNews/mainColumnParagraphs/015/text_files/file/document/AddressingSocietalChallenges_FINAL .pdf

[7] T. Golja, "Designing transdisciplinary programs to drive innovation," in ICER/2014 Proceedings, pp. 958-968, 2014.

[8] T. Golja, S. McClean, and K. Jordan, "Collective learning in an industry-education-research test bed," in Transdisciplinary Theory, Practice and Education: The Art of Collaborative Research and Collective Learning (D. Fam, L. Neuhauser, and P. Gibbs, eds.), pp. 185-199, Germany: Springer, 2018.

[9] Australian Government, Department of Education, Skills and Employment, Future ready: $A$ student focused national career education strategy, 2019. Retrieved from https://docs.education.gov.au/node/52421

[10] P. Barrett, Learning pathways support: 'Career advice', CEDP, April 2019.

[11] P. Barrett, Enterprise learning: A staged approach, CEDP, August 2019.

[12] P. Barrett, Enterprise learning: Leveraging system programs, CEDP, August 2019.

[13] OECD. Career Guidance, Education GPS, 2019. Retrieved from https://gpseducation.oecd.org/revieweducationpolicies/\#!node=42868\&filter=All 
[14] MCEECDYA, The Australian blueprint for career development, Australian Government: Department of Education, Employment and Workplace Relations, 2010. Retrieved from https://www.education.gov.au/australian-blueprint-career-development

[15] O. Scharmer, and K. Kaufer, Leading from the emerging future. Oakland, CA: Berrett-Koehler Publishers, 2013.

[16] D. Gonski, Through growth to achievement: Report of the review to achieve education excellence in Australian schools, Australian Government: Department of Education, Skills and Employment, 2018. Retrieved from https://docs.education.gov.au/documents/through-growth-achievementreport-review-achieve-educational-excellence-australian-0

[17] Education Council. Review of the Melbourne Declaration on Educational Goals for Young Australians, 2019. Retrieved from https://www.reviewmelbournedeclaration.edu.au

[18] Australian Government, Department of Education, Skills and Employment. Australian Education Act 2013. Accessed 22 September 2020. Retrieved from https://www.education.gov.au/australianeducation-act-2013

[19] Australian Curriculum, General Capabilities. Accessed 22 September 2020. Retrieved from https://www.australiancurriculum.edu.au/f-10-curriculum/general-capabilities/

[20] Australian Government, Department of Education, Skills and Employment, Trade Training Centres in Schools Program. Accessed 22 September 2020. Retrieved from https://www.education.gov.au/trade-training-centres-schools-program

[21] Deloitte, The path to prosperity: Why the future of work is human, 2019. Retrieved from https://www2.deloitte.com/au/en/pages/building-lucky-country/articles/path-prosperity-futurework.html

[22] M. Anderson, B. Hinz, and H. Matus, The paradigm shifters: Entrepreneurial learning in schools, Mitchell Institute, 2017. Retrieved from https://www.originfoundationknowledgehub.org.au/cms_uploads/docs/paradigmshifters_entrepreneurial-learning-in-schools.pdf

[23] J. Buchanan, R. Ryan, M. Anderson, R. Calvo, N. Glozier, and S. Peter, Future frontiers analytical report: Preparing for the best and worst of times, NSW Government, 2018. Retrieved from https://education.nsw.gov.au/content/dam/main-education/teaching-and-learning/education-for-achanging-world/media/documents/Future-Frontiers_University-of-Sydney-report.pdf

[24] E. Douglas, CEO perspectives: The future of schooling in Australia, AIS NSW, 2018. Retrieved from https://www.aisnsw.edu.au/Resources/WAL\%204\%20[Open\%20Access]/CEO\%20Perspectives\% 20-\%20The\%20Future\%20of\%20Schooling\%20In\%20Australia\%20Report.pdf

[25] K. Torii, Connecting the worlds of learning and work: Prioritising school-industry partnerships in Australia's education system, Mitchell Institute, 2018. Retrieved from https://cica.org.au/wpcontent/uploads/Connecting-the-Worlds-of-Learning-and-Work.pdf

[26] CSIRO, Australian national outlook 2019: Securing our nation's future prosperity, 2019. Retrieved from https://www.csiro.au/en/Showcase/ANO

[27] P. Harris, Shifting the Dial, Australian Government: Productivity Commission, 2017. Retrieved from https://www.pc.gov.au/inquiries/completed/productivity-review/report

[28] National Careers Institute Partnership Grants, Grant Opportunity Guidelines, 2020. Retrieved from https://business.gov.au/Grants-and-Programs/National-Careers-Institute-Partnership-Grants

[29] M. Cosgrove, and L. Schaverien, "Children's conversations and learning science and technology," International Journal of Science Education, vol. 18, no. 1, pp. 105-116, 1996.

[30] T. Golja, and L. Schaverien, "Theorising professional development in the academy: a conversational approach," in AARE 2005 Creative Dissent: Constructive Solutions Proceedings, pp. 1-23, 2005.

[31] L. Barratt-Pugh, "The measurement of learning conversations: The illusions of the absolute, obscures meaning," in AVETRA Conference Proceedings: Quality and diversity in VET research, pp. 1-7, 1999. 
[32] H. Christiansen, and J. Devitt, "Collaborative conversations at the university: Creating a pedagogical space," in Recreating Relationships: Collaboration and Educational reform $(\mathrm{H}$. Christiansen, J. Goulet, C. Krentz, and M. Maeers, eds.), pp. 167-180, Albany: State University of New York Press, 1997.

[33] C. Clark, ed. Talking shop: Authentic conversation and teacher learning. New York: Teachers College Press, 2001.

[34] N. Haigh, "Everyday conversation as a context for professional learning and development," International Journal of Academic Development, vol. 10, no. 1, pp. 3-16, 2005.

[35] A. Lieberman, and L. Miller, eds., Teachers caught in the action: Professional development that matters. New York: Basic Books, 2001.

[36] R. Putnam, and H. Borko, "What do new views of knowledge and thinking have to say about research on teacher learning?" Educational Researcher, vol. 29, no. 1, pp. 4-15, 2000.

[37] L. Schaverien, and M. Cosgrove, "Learning to teach generatively: Mentor-supported professional development and research in technology-and-science," Journal of the Learning Sciences, vol. 6, no. 3, pp. 317-346, 1997.

[38] T. Zeldin, Conversation. London: The Harvill Press, 1998.

[39] R. Scholz, "Mutual learning as a basic principle of transdisciplinarity," in Transdisciplinarity: Joint Problem-Solving Among Science, Technology and Society (R. Scholz, R. Häberli, A. Bill, and M. Welti, eds.,), Proceedings of the International Transdisciplinarity 2000 Conference. Workbook II: Mutual Learning, pp. 13-17, Zürich: Haffman, 2000.

[40] T. Davenport, and J. Kirby, J. "Beyond automation," Harvard Business Review, vol. 94, no. 6, pp. 59-65, 2015.

[41] McKinsey Global Institute, A future that works: Automation, employment, and productivity, McKinsey \& Company, January 2017. Retrieved from https://www.mckinsey.com/ /media/mckinsey/featured\%20insights/Digital\%20Disruption/Harnessi ng\%20automation\%20for\%20a\%20future\%20that\%20works/MGI-A-future-that-works-Fullreport.ashx

[42] E. Eisner, The enlightened eye: Qualitative inquiry and the enhancement of educational practice. Upper Saddle River, NJ: Merrill, 1998.

[43] T. Barone, and E. Eisner, "Chapter 5: Arts-based educational research," in Handbook of Complementary Methods in Educational Research (J. Green, G. Camilli, and P. Elmore, eds.), pp. 95-109, Mahwah, NJ: Lawrence Erlbaum Associates, 2006.

[44] E. McMullin, "Values in science," in PSA: Proceedings of the Biennial Meeting of the Philosophy of Science Association, vol. 2: Symposia and Invited Papers, pp. 3-28, 1982.

[45] A. Shenton, "Strategies for ensuring trustworthiness in qualitative research projects," Education for Information, vol. 22, pp. 63-75, 2004.

[46] G. Howard, "The role of values in the science of psychology," American Psychologist, vol. 40, no. 3, pp. 255-265, 1985.

[47] M. Hammersley, "Chapter 4: By what criteria should ethnographic research be judged?" in What's Wrong with Ethnography? Methodological Explorations (M. Hammersley), pp. 57-82, London: Routledge, 1992. 